\title{
Extraction of Remaining Teeth and Same Day Loading of Neoss Proactive Dental Implants with a Full-arch Fixed Provisional Bridge. A Survival Analysis
}

\author{
Pierluigi Coli ${ }^{1}$ and Lars Sennerby ${ }^{1,2 *}$ \\ ${ }^{1}$ Edinburgh Dental Specialists, Edinburgh, UK \\ 2Department of Oral \& Maxillofacial Surgery, University of Gothenburg, Gothenburg, Sweden.
}

${ }^{\star}$ Corresponding author: Department of Oral \& Maxillofacial Surgery, Sahlgrenska Academy, University of Gothenburg, PO Box 450, SE405 30 Gothenburg, Sweden; E-mail: lars.sennerby@gu.se

Received: June 17, 2019; Accepted: June 26, 2019; Published: July 01, 2019;

\begin{abstract}
Removal of remaining teeth and same day loading of an implant-supported full-arch bridge may be a sensible treatment modality for many patients presenting with a severely diseased partial dentition. The aim of the present study was to retrospectively analyse 30 consecutive patients (21 female/ 9 male, mean age $61.9+11.1$ years) subjected to removal of all remaining teeth, placement of four to six implants and loading of a full-arch provisional bridge the same day. A total of 156 dental implants (Proactive Straight, Neoss Ltd, Harrogate, UK) 3.5 to $5 \mathrm{~mm}$ in diameter and 9 to $13 \mathrm{~mm}$ in lengths were placed in 21 maxillae and 14 mandibles. Provisional acrylic bridges were fabricated in the in-house dental laboratory and fitted after a few hours from the surgical procedures using screw retention. The fabrication of the definitive prostheses was initiated between three to six months from the implant placement. A total of four implants failed in three patients during the initial healing period with provisional bridges in place, giving a cumulative survival rate of $97.3 \%$ during a mean follow-up period of $3.5+1.0$ years (range $2-5$ years). Two failures occurred in the maxilla as a result of fracture of the provisional bridge and two in the mandible due to infection. These three patients had new implants placed and could maintain the repaired or a new provisional bridge during the additional healing period. A total of seven provisional acrylic bridges fractured. No implant failures were observed after placement of the permanent fixed bridges. Few minor other complications occurred during the follow-up. It is concluded that the evaluated treatment concept resulted in a high implant survival rate and few complications after a follow-up of 2 to 5 years. Although not quantified, the positive effects on self-esteem and psychosocial wellbeing was obvious.
\end{abstract}

Keyword: Dental Implants, Full-Arch Bridge, Follow-Up Study, Extraction Sockets, Immediate Loading, Screw-Retained Prosthesis

\section{Introduction}

Today, most patients can be offered replacement of lost teeth with fixed implant-supported prostheses using swift and safe procedures irrespective of the conditions of the edentulous areas [1]. This is thanks to developments of the original strict osseointegration protocol [2], which was thoroughly evaluated in clinical studies and proven to be highly successful, initially in totally edentulous jaws [3] and later in partially dentate patients $[4,5]$ Long healing periods were originally advocated after tooth extraction as well as after implant placement in order to assure osseointegration of the implants prior to loading [6]. Further development and evaluation of improved implant surfaces, regenerative techniques and treatment protocols have resulted in the possibility to dramatically reduce treatment times without jeopardizing the outcomes [1]. For instance, implants can be placed immediately in extraction sockets $[7,8]$ and loaded the same day or a few days after installation $[9,10]$. However, although immediate/ early loading of dental implants has evident benefits for the patient, it is a resource demanding procedure, as it requires a well-planned collaboration between the clinical team and the dental technician.
In fact, it is a logistic challenge to offer immediate/early loading to all implant patients in a busy dental practice. Since the majority of implant patients are missing one or a few teeth [11-13], fixed or removable provisional prostheses can be made and used during the implant healing period.

The present authors have identified one group of patients in whom immediate loading is justified and highly effective. These patients typically presents with a severely diseased partial dentition in one or both jaws. Apart from the functional aspects with impaired chewing comfort, the aesthetic appearance may have led to low self-esteem, depression and a decline in psychosocial wellbeing [14]. Moreover, the patients may not have seen a dentist for a long time due to severe dental fear. It is our experience that these patients can be motivated to go through one surgical procedure including removal of remaining teeth and placement of implants followed by the manufacturing and loading of a provisional bridge the same day as reported by other authors [15-17]. Systematic reviews have concluded that immediate/ early loading is a straightforward approach in the mandible [18], while treatment of the maxilla is less well documented [19-21], particularly 
when implants are placed in extraction sockets [21]. However, numerous studies have reported survival rates from $98 \%$ to $99 \%$ when placing implants in extraction and healed sites for immediate loading of maxillary full-arch constructions [22-25], while other studies have shown less good outcomes with increased failure rates in the maxilla $[26,27]$ and for implants in extraction sockets [28].

The aim of the present study was to retrospectively analyse implant survival and technical complications in 30 consecutive patients treated with same day loading of full-arch implant-supported temporary bridges in conjunction with tooth extractions.

\section{Materials \& Methods}

\section{Patients and data collection}

This retrospective study includes consecutive patients treated with an immediately loaded fixed full-arch bridge on Neoss implants (Proactive Straight, Neoss Ltd, Harrogate, UK) in conjunction with extraction of remaining teeth in the maxilla and/or mandible at the Edinburgh Dental Specialist referral clinic, Edinburgh, Scotland and with at least two years of follow-up.

Patient data were collected from the charts and entered into spreadsheets. Gender, age, diagnosis of the failing dentition, surgical date, number of teeth extracted, implant location, insertion torque, implant dimensions, abutment type and angulation, implant and restorative complications or failures were recorded. The study was made in accordance with the World Medical Association Declaration of Helsinki.

At the initial consultation, the patients signed a general consent form for data collection. A comprehensive medical history assessment was made. The clinical examination included an oral cancer screen, intraoral radiographs, comprehensive dental and periodontal examinations. Photographs were taken as well as impressions for diagnostic models (Figure 1). An initial treatment plan was outlined by the prosthodontist (PC) and presented and discussed with the patient. The presurgical patient evaluation with the implant surgeon (LS) consisted of a comprehensive oral examination and the use of orthopantomographic and/or cone beam computed tomographic (CBCT) scans. The only exclusion criteria applied was the insufficient bone availability for implant placement as evaluated initially on orthopantomographic assessment and confirmed by CBCT imaging.

\section{Clinical procedures}

The treatment consisted in the extraction of the remaining dentition in the dental arch and the immediate placement of four to six dental implants in the maxilla and four to five in the mandible (Figure 2). (Neoss Proactive Straight, Neoss Ltd, Harrogate, UK). The final number of implants to be placed in the particular case was decided by the surgeon during the surgical procedures, depending on the bone quantity and quality, on the implant distribution in the dental arch and on the initial implant stability. The implants were placed both in healed and extracted sites in order to achieve a good distribution of the implants within the jaw. The implants were typically placed between the maxillary sinuses and the mental foramina.
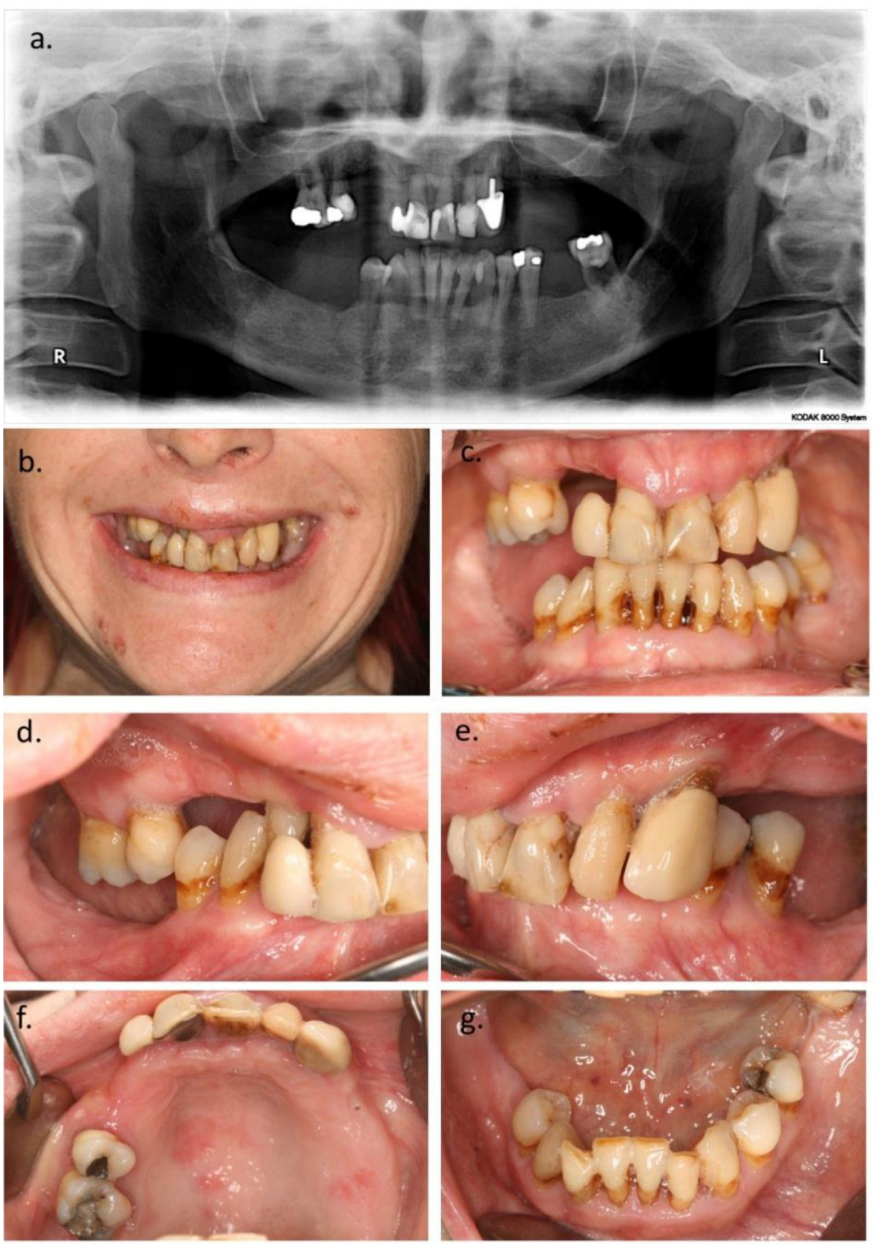

Figure 1. 48 year old female patient at initial consultation for treatment of both jaws. a Orthopanthomogram, b. Extraoral appearance. c. Intraoral view. d. Left and e. right side. f. Occlusal view of upper and g. lower jaw.
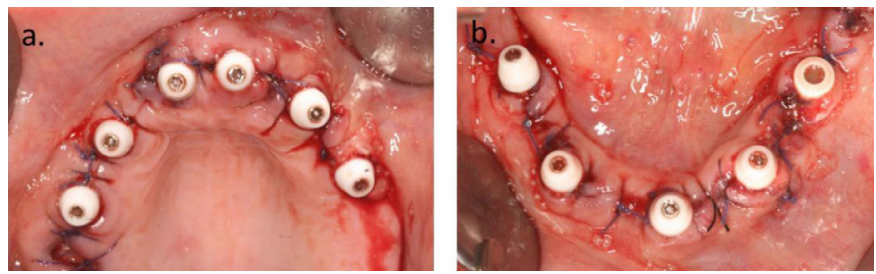

Figure 2. Intraoral view after extractions of remaining teeth (see Figure 1a) and implant surgery, which was made at two different occasions with 6 weeks in between. a. Upper jaw with six implants and prosthetic abutments. b. Lower jaw with five implants and abutments.

Screw-retained transmucosal abutments (Access, Neoss Ltd, Harrogate, UK or Multi Unit Abutments, Nobel Biocare UK Ltd, Uxbridge, UK) were placed on the implants. Most of the abutments were straight, whereas angulated abutments were used to compensate for the intentionally tilted posterior implants (to avoid maxillary sinuses or mandibular nerve infringements) or to correct the angulation of forward positioned anterior implants. Resorbable sutures were used for soft tissue closure.

Directly after the placement of the transmucosal abutments, working impressions of the implant positions were taken with Impregum (3M Ltd, London, UK). The occlusal vertical dimension was registered in different ways. By using one remaining tooth to be 
extracted (or refitting the extracted tooth in the extraction socket) in case the original vertical dimension was acceptable. When there was the need of an increase in the vertical dimension, temporary cylinders sectioned at the wished length and fitted onto the transmucosal abutments were used to provide a stable bite registration. The provisional acrylic bridges were fabricated in the in-house dental laboratory and fitted after a few hours from the surgical procedures using screw retention (Figure 3). The distal extension of the temporary bridges was limited to the most distal implant position to prevent acrylic fractures and maintain the occlusal load to the minimum. The fit and occlusion were checked and adjusted as needed. Provisional fillings were placed in the access holes and the patient was discharged with instructions to follow a soft food diet for the time the temporary bridge was in use.
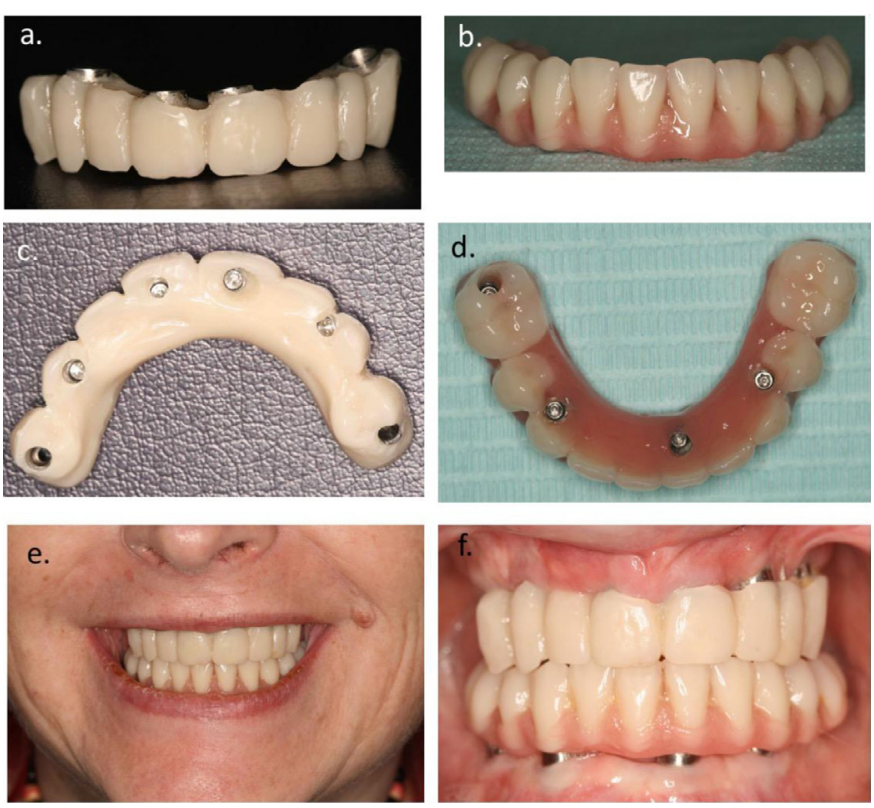

Figure 3. a. Provisional acrylic bridge for the upper and b. lower jaw. c. Occlusal views of upper and d. lower bridge. e. Extraoral and f. intraoral appearance with both provisional bridges fitted on the implants.

\section{Post-operative protocol}

Post-surgical prescriptions consisted of analgetic drugs in case of pain (brufen 400mg x4 or paracetamol 1gr x4) and a five-day course of antibiotics (amoxicillin $750 \mathrm{mg}$ x2 or clindamycin $150 \mathrm{mg}$ x2). Patients were seen 1-2 weeks following surgery to assess the healing process and the functionality of the temporary bridge (aesthetics, occlusion, vertical dimension) as well as to address any potential concerns regarding swelling and bruising. Patients were encouraged to contact the clinic in case any mobility of the bridge or portions of the bridge were experienced. In such a case, the bridge was carefully removed and the implant conditions assessed. In case of bridge fractures, the bridge was repaired in the dental laboratory and refitted after a few hours. In case of implant mobility, the implant was removed and later replaced with a new one.

\section{Final bridges}

The fabrication of the definitive prostheses was initiated between three to six months from the implant placement, depending on the amount of soft and hard tissue recession expected after surgery, on the jaw (maxilla or mandible), on the time availability from the patient's and the prosthodontist's sides.

At the removal of the temporary bridge, the stability of the implant/ transmucosal abutment complex was verified and the conditions of the peri-implant soft tissues assessed. In the absence of mobility, pain, suppuration at palpation/pressure, the implants were considered ready to support a definitive restoration, which was fabricated during three to four appointments. This would include (i) final impressions, (ii) articulation of the working models in the laboratory using the provisional prostheses as guidance and (iii) insertion of the definitive bridge or (i) final impressions, (ii) bite registration, (iii) wax trial and (4) insertion of the definitive bridge. At the time of the final impressions, the proper fit of the impression copings onto the transmucosal abutments or onto the implants as well as the periimplant bone level were checked with intraoral radiographs.

Three different types of definitive bridges could be provided:

(i) A titanium framework and acrylic resin denture base material with denture teeth around it,

(ii) A monolithic zirconia framework with porcelain bonded on it

(iii) A chrome-cobalt framework with porcelain bonded on it.

The bridges were screw-retained onto the transmucosal abutments or directly onto the implants after the removal of the transmucosal abutments (Figure 4,5), depending on the amount of soft tissue recession that had occurred during healing and on the aesthetic demands. The fit of the bridge to the transmucosal abutments/implants was verified with intraoral radiographs that would also provide for baseline peri-implant bone levels.
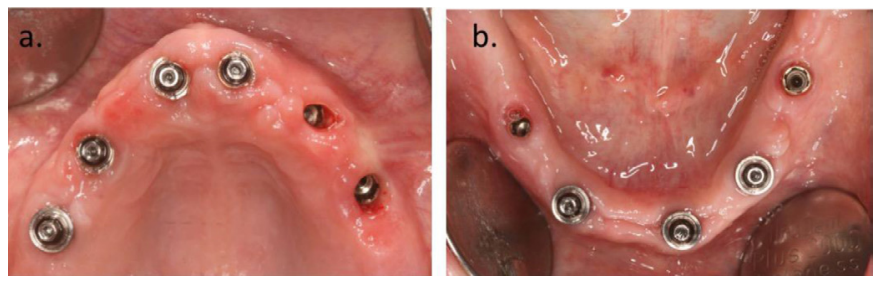

Figure 4. a. Soft tissue situation at the time of fitting the final bridges in the upper and b. lower jaw.

\section{Follow-ups}

A follow-up appointment was carried out after 3-4 weeks from the provision of the definitive bridge for a control tightening of the screws and the provision of permanent fillings onto the access holes. Patients were thereafter scheduled for recalls once a year the first two years, thereafter at the fifth, seventh, $10^{\text {th }}$ anniversary and every $2-3$ years thereafter. At these appointments, assessments of the integrity of the prostheses and of the soft and hard peri-implant tissues conditions by clinical and radiographic examinations were carried out.

\section{Results}

A total of 30 patients ( 21 female/ 9 male, mean age $61.9+11.1$ years) were included in the study. Five patients had been treated in both jaws at two different occasions. On average, seven teeth $(7.7+$ 
2.8) were extracted in each jaw and treated with 156 implants (Neoss Ltd, Harrogate, UK), where 93 had been placed in the maxilla (21 jaws) and 63 in the mandible (14 jaws) (Table 1). In five cases, previously placed implants were included in the bridge.
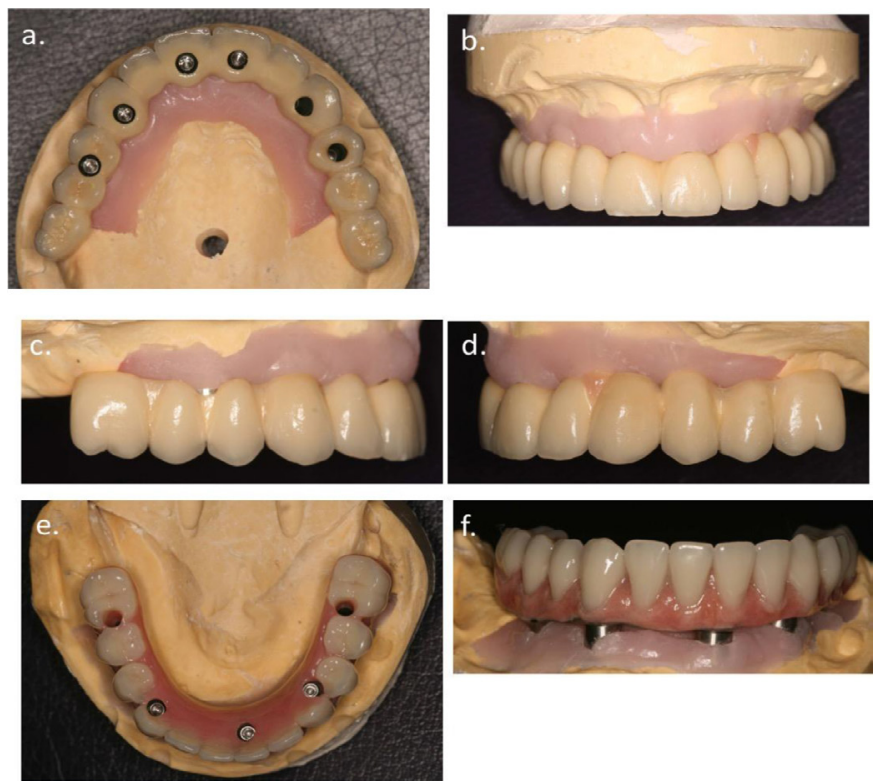

Figure 5. a-d. Showing the final bridge in the upper and e-f. the lower jaw.
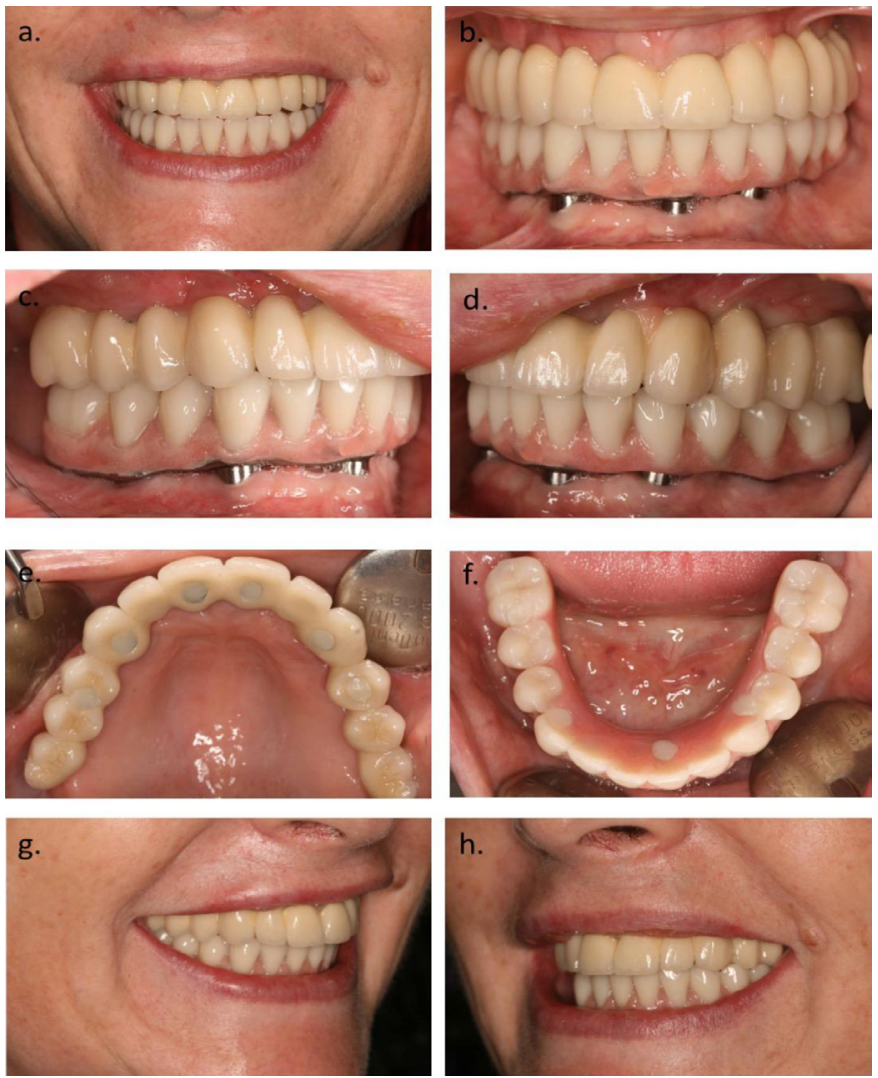

Figure 6. a. Extraoral view with final bridges fitted. b Intraoral frontal view, c. Right and d. left side. e. Occlusal view of the upper and f. lower bridges. g. Oblique extraoral view of final bridges.

A total of four implants failed in three patients during the follow-up period giving a cumulative survival rate of $97.4 \%$ after a mean follow- up of $3.5+1.0$ years (range $2-5$ years) (Table 2). All implant failures occurred during the initial healing period with temporary bridges in place. Two failures occurred in the maxilla $(2.2 \%)$ in two patients as a result of fracture of the temporary bridge and two in the mandible ( $3.2 \%)$ in one patient due to infection. These three patients had new implants placed and could maintain the repaired bridge $(n=2)$ or got a newly made temporary bridge including the newly placed implants $(\mathrm{n}=1)$ during the additional healing period. No implant failures were observed after placement of the permanent fixed bridges.

Table 1. Number and type of implants placed. Failed implants within brackets.

\begin{tabular}{|l|c|c|c|c|c|}
\hline Length & $\begin{array}{c}3.5 \\
\mathrm{~mm}\end{array}$ & $4.0 \mathrm{~mm}$ & $\begin{array}{c}4.5 \\
\mathrm{~mm}\end{array}$ & $\begin{array}{c}5.0 \\
\mathrm{~mm}\end{array}$ & Sa \\
\hline $9 \mathrm{~mm}$ & & 2 & 1 & 1 & 4 \\
\hline $11 \mathrm{~mm}$ & 3 & 14 & 1 & & 18 \\
\hline $13 \mathrm{~mm}$ & 10 & $116(4)$ & 8 & & 134 \\
\hline Sa & 13 & 132 & 10 & 1 & 156 \\
\hline
\end{tabular}

Table 2. Implant survival. Life table analysis.

\begin{tabular}{|l|c|c|c|c|}
\hline \multicolumn{1}{|c|}{ Interval } & Implants & Failed & $\begin{array}{c}\text { Not yet } \\
\text { due }\end{array}$ & CSR \\
\hline Insertion to final bridge & 156 & 4 & 0 & $97.4 \%$ \\
\hline Final bridge to 1 year & 152 & 0 & 0 & $97.4 \%$ \\
\hline 1 to 2 years & 152 & 0 & 31 & $97.4 \%$ \\
\hline 2 to 3 years & 121 & 0 & 31 & $97.4 \%$ \\
\hline 3 to 4 years & 90 & 0 & 68 & $97.4 \%$ \\
\hline 4 to 5 years & 22 & & & \\
\hline
\end{tabular}

Although not quantified in the present study, the peri-implant marginal bone levels were maintained throughout the observation period with the exception of one anterior mandibular fixture showing a bone loss of $2 \mathrm{~mm}$ mesially and distally at the 1-y recall compared to the bone levels observed at the time of the fit of the permanent bridge. The fixture did not show any further bone loss at the subsequent recall appointments. From a prosthetic point of view, in seven patients the provisional acrylic prostheses fractured during the healing time. Two of these patients experienced two fractures and one patient three fractures of the same prosthesis. In two cases the fractures of the provisional restorations corresponded to the osseointegration failure of the implant supporting the fractured portion.

The lower jaws were all but one restored with titanium/acrylic prostheses. Fifteen upper jaws were restored with titanium/acrylic prostheses, five with metal/ceramic prostheses and one with a zirconia restoration.

During the follow-up period, four patients experienced the fracture of an acrylic tooth from the permanent restoration (one patient had three fractures of one acrylic tooth). In all cases, the prostheses were repaired in the laboratory within few hours and refitted the same day. 


\section{Discussion}

In the present retrospective study, 30 patients received a total of 35 immediately loaded fixed implant-supported provisional bridges in conjunction with extraction of remaining teeth and were evaluated after 2 to 5 years. All provisional bridges could be maintained as planned during the initial period of 3 to 6 months in spite of four implant osseointegration failures, although the involved bridges had to be repaired and adjusted. No additional failures occurred after connection of the final bridges, giving an implant survival rate of 97.4 $\%$ with small differences between the maxilla and mandible after a mean follow-up of 3.5 years. The four failures in the present study were due to fracture of the provisional bridge and subsequent overload in two maxillary cases and infection in one mandible.

The same treatment modality has been evaluated by other authors in previous publications, which have shown varying clinical results and especially in the maxilla [23-28]. The reasons for the different outcomes may be attributed to differences in patient selection, inclusion criteria and the type/number of implants that were used. For instance, Balshi et al [23] placed a mean of 10 implants per patient and reported a survival rate of $99 \%$, while studies with lower survival rates in general used fewer implants [29]. It is also known that implant surface topography has an impact on implant healing [30-31] and clinical outcome [32], which may explain differences between studies. For instance, Andersson et al [33] used a similar concept as in the present study in 55 patients but where the Neoss implants were loaded 1-3 days after extractions and implant placement. They reported a survival rate of $93.7 \%$ after a mean follow-up of 2.9 years, which is lower than in the present study. Although utilising the same implant design as in our study, they used two different surfaces (Bimodal vs Proactive) and observed better results with the Proactive surface, 96.4 $\%$ vs $89.7 \%$ for the Bimodal surface. They speculated that this could be explained by differences in surface topography as well as chemical properties of the two surfaces, as the Proactive surface is rougher and hydrophilic compared to the smoother and hydrophobic Bimodal surface. Experimental and clinical studies have shown a stronger bone tissue response to the Proactive surface, which showed more bone contacts and higher stability as measured with removal torque tests and resonance frequency analysis (RFA) measurements [34, 35]. In addition, clinical studies have also demonstrated higher stability [36] and better clinical outcomes [37] with Neoss Proactive than with Bimodal implants. However, like in our study, all patients received and maintained a fixed bridge in spite of the implant failures in the Andersson et al study.

From a prosthetic point of view, the maintenance of the implantretained prosthesis can be viewed as the primary objective of the treatment. In such a case, the survival rate of the restorations described in this study was $100 \%$, with very few minor prosthetic complications that could be amended within few hours. These data are very similar to the data presented by Tealdo and co-workers who reported of a $100 \%$ fixed prostheses survival and minor fractures, easily adjusted, in a 6-year prospective study on immediate or delayed implant load on maxillary edentulous patients [38].

The immediate effect of the provision of an immediate fixed restoration on the patient's life quality should not be underestimated.
It is well documented that insertion of an implant-supported bridge in the edentulous patient results in marked psychological and social improvement when using the original and lengthy protocol [39]. Many of the patients in this investigation had a history of poor functioning removable prostheses, constant discomfort and often pain due to failing dentition, low self-esteem and limited social life. The one-day treatment approach had a dramatic effect as it clearly improved the subject life quality and self-esteem almost immediately.

It is concluded that extraction of remaining teeth and same day loading of a provisional full-arch bridge resulted in a high implant survival rate and few complications in both the mandible and maxilla after a follow-up of 2 to 5 years. Although not quantified, the positive effects on self-esteem and psychosocial wellbeing was obvious.

\section{References}

1. Buser D, Sennerby L, De Bruyn H (2017) Modern implant dentistry based on osseointegration: 50 years of progress, current trends and open questions. Periodontol 2000 73: 7-21. [crossref]

2. Brånemark PI, Hansson BO, Adell R, Breine U, Lindström J, et al. (1977) Osseointegrated implants in the treatment of the edentulous jaw. Experience from a 10-year period. Scand J Plast Reconstr Surg 16: 1-132.

3. Adell R, Lekholm U, Rockler B, Brånemark PI (1981) A 15-year study of osseointegrated implants in the treatment of the edentulous jaw. Int J Oral Surg 10: 387-416. [crossref]

4. Lekholm U, Gunne J, Henry P, Higuchi K, Lindén U, et al. (1999) Survival of the Brånemark implant in partially edentulous jaws: a 10-year prospective multicenter study. Int J Oral Maxillofac Implants 14: 639-645. [crossref]

5. Henry PJ, Laney WR, Jemt T, Harris D, Krogh PH, et al. (1996) Osseointegrated implants for single-tooth replacement: a prospective 5-year multicenter study. Int $J$ Oral Maxillofac Implants 11: 450-455. [crossref]

6. Adell R, Lekholm U, Brånemark PI (1987) Surgical procedures. In Brånemark, PerIngvar; Zarb, George A.; Albrektsson, Tomas (eds.) Tissue-Integrated Prostheses: Osseointegration in Clinical Dentistry, Chicago, Quintessence, pp: 211-232.

7. Chrcanovic BR, Albrektsson T, Wennerberg A (2015) Dental implants inserted in fresh extraction sockets versus healed sites; a systematic review and meta-analysis. J Dent 43: 16-41.

8. Chen H, Zhang G, Weigl P, Gu X (2018) Immediate placement of dental implants into infected versus noninfected sites in the esthetic zone: A systematic review and meta-analysis. J Prosthet Dent 120: 658-667. [crossref]

9. De Bruyn H, Raes S, Ostman PO, Cosyn J (2014) Immediate loading in partially and completely edentulous jaws: a review of the literature with clinical guidelines. Periodontol 2000 66: 153-187. [crossref]

10. Huynh-Ba G, Oates TW, Williams MAH (2018) Immediate loading vs. early/ conventional loading of immediately placed implants in partially edentulous patients from the patients' perspective: A systematic review. Clin Oral Implants Res 16: 255-269.

11. Hugoson A, Koch G, Go"thberg C, Helkimo AN, Lundin SA, et al. (2005) Oral health of individuals aged 3-80 years in Jo"nko" ping, Sweden during 30 years (1973-2003). Part II: Review of clini- cal and radiographic findings. Swed Dent J 29: 139-155.

12. Mack F, Samietz SA, Mundt T, Proff P, Gedrange T, et al. (2006) Prevalence of single-tooth gaps in a population-based study and the potential for dental implants-data from the Study of Health in Pomerania (SHIP-0). J Craniomaxillofac Surg 34 Suppl 2: 82-85. [crossref]

13. O*sterberg T, Carlsson GE (2007) Dental state, prosthodontic treatment and chewing ability - a study of five cohorts of 70 -year-old subjects. J Oral Rehabil 34: 553-559.

14. Emami E, de Souza RF, Kabawat M, Feine JS (2013) The impact of edentulism on oral and general health. Int J Dent 2013: 498305. [crossref]

15. Balshi TJ, Wolfinger GJ (1997) Immediate loading of Brånemark implants in edentulous mandibles: a preliminary report. Implant Dent 6: 83-88. [crossref]

16. Wolfinger GJ, Balshi TJ, Rangert B (2003) Immediate functional loading of Brånemark system implants in edentulous mandibles: clinical report of the results of developmental and simplified protocols. Int J Oral Maxillofac Implants 18: 250-257. [crossref]

17. Olsson M, Urde G, Andersen JB, Sennerby L (2003) Early loading of maxillary fixed cross-arch dental prostheses supported by six or eight oxidized titanium implants: results after 1 year of loading, case series. Clin Implant Dent Relat Res 5 Suppl 1: 81-87 
18. Papaspyridakos P, Mokti M, Chen CJ, Benic GI, Gallucci GO, et al. (2014) Implant and prosthodontic survival rates with implant fixed complete dental prostheses in the edentulous mandible after at least 5 years: a systematic review. Clin Implant Dent Relat Res 16: 705-717. [crossref]

19. Attard NJ, Zarb GA (2005) Immediate and early implant loading protocols: a literature review of clinical studies. J Prosthet Dent 94: 242-258.

20. Ostman PO (2008) Immediate/early loading of dental implants. Clinical documentation and presentation of a treatment concept. Periodontol 2000 47: 90-112. [crossref]

21. Strub JR, Jurdzik BA, Tuna T (2012) Prognosis of immediately loaded implants and their restorations: a systematic literature review. J Oral Rehab 39: 704-717.

22. Degidi M, Piattelli A, Felice P, Carinci F (2005) Immediate functional loading of edentulous maxilla: a 5 -year retrospective study of 388 titanium implants. $J$ Periodontol 76: 1016-1024.

23. Balshi SF, Wolfinger GJ, Balshi TJ (2005) A prospective study of immediate functional loading following the Teeth-in-a-Day protocol: a case series of 55 consecutive edentulous maxillas. Clin Implant Dent Relat Res 7: 24-31.

24. Agliardi EL, Pozzi A, Stappert CFJ, Benzi R, Romeo D, et al. (2014) Immediate fixed rehabilitation of the edentulous maxilla: a prospective clinical and radiological study after 3 years of loading. Clin Implant Dent Relat Res 16: 292-302.

25. Gillot L, Canna B, Buti J, Noharet R (2012) A retrospective cohort study of 113 patients rehabilitated with immediately loaded maxillary cross-arch fixed dental prostheses in combination with immediate implant placement. Eur J Oral Implantol 5: 71-79.

26. Grunder U (2001) Immediate functional loading of immediate implants in edentulous arches: two-year results. Int J Periodontics Restorative Dent 21: 545 551.

27. Covani U, Orlando B, D'Ambrosio A, Sabattini VB, Barone A (2012) Immediate rehabilitation of completely edentulous jaws with fixed prostheses supported by implants placed into fresh extraction sockets and healed sites: a 4-year evaluation. Implant Dent 21: 272-279.

28. Ji TJ, Kan JY, Rungcharassaeng K, Roe P, Lozada JL (2012) Immediate loading of maxillary and mandibular implant-supported fixed complete dentures: a 1- to 10year retrospective study. J Oral Implantol 38: 469-477.
29. De Bruyn H, Raes S, Ostman PO, Cosyn J (2014) Immediate loading in partially and completely edentulous jaws: a review of the literature with clinical guidelines. Periodontol 2000 66: 153-187. [crossref]

30. Zechner W, Tangl S, Fürst G, Tepper G, Thams U, et al. (2003) Osseous healing characteristics of three different implant types. Clin Oral Implants Res 14: 150157. [crossref]

31. Burgos PM, Rasmusson L, Meirelles L, Sennerby L (2008) Early bone tissue responses to turned and oxidized implants in the rabbit tibia. Clin Implant Dent Relat Res 10: 181-190. [crossref]

32. Jemt T, Olsson M, Franke Stenport V (2015) Incidence of First Implant Failure: A Retroprospective Study of 27 Years of Implant Operations at One Specialist Clinic. Clin Implant Dent Relat Res 17 Suppl 2: e501-510.

33. Andersson P, Degasperi W, Verrocchi D, Sennerby L (2015) A Retrospective Study on Immediate Placement of Neoss Implants with Early Loading of Full-Arch Bridges. Clin Implant Dent Relat Res 17: 646-657. [crossref]

34. Grossi-Oliveira GA, Antunes AA, Elias CN, Wennerberg A, Sennerby L, et al. (2015) Early Osseointegration Events on Neoss ${ }^{\circledR}$ ProActive and Bimodal Implants: A Comparison of Different Surfaces in an Animal Model. Clin Implant Dent Relat Res 17: 1060-1072.

35. Sennerby L, Gottlow J, Gottlow J (2017) Integration of Neoss ProActive implants in comparison with other brands of dental implants. Letters Implant Dent 1: 7-20.

36. Vanden Bogaerde L, Sennerby L (2016) A Randomized Case-Series Study Comparing the Stability of Implant with Two Different Surfaces Placed in Fresh Extraction Sockets and Immediately Loaded. Int J Dent 2016: 8424931. [crossref]

37. Zumstein T, Sahlin H (2017) The evolution of the Neoss implant system: A retrospective follow-up of three patient cohorts treated with three types of Neoss implants. Letters Implant Dent 1: 35-37.

38. Tealdo T, Menini M, Bevilacqua M, Pera F, Pesce P, et al. (2014) Immediate versus delayed loading of dental implants in edentulous patients' maxillae: a 6-year prospective study. Int J Prosthodont 27: 207-214. [crossref]

39. Blomberg S (1987) Psychological response. In Brånemark, Per-Ingvar; Zarb, George A.; Albrektsson, Tomas (eds) Tissue-Integrated Prostheses: Osseointegration in Clinical Dentistry, Chicago, Quintessence, pp: 16.

\section{Citation:}

Coli P and Sennerby L(2019) Extraction of Remaining Teeth and Same Day Loading of Neoss Proactive Dental Implants with a Full-arch Fixed Provisional Bridge. A Survival Analysis. J Dent Maxillofacial Res Volume 2(2): 1-6. 